\title{
Outcomes of Locoregional Tumor Therapy for Patients with Hepatocellular Carcinoma and Transjugular Intrahepatic Portosystemic Shunts
}

\author{
Siddharth A. Padia $\cdot$ Rush H. Chewning • Matthew J. Kogut • Christopher R. Ingraham • \\ Guy E. Johnson - Renuka Bhattacharya - Sharon W. Kwan • Wayne L. Monsky • \\ Sandeep Vaidya $\cdot$ Daniel S. Hippe $\cdot$ Karim Valji
}

Received: 20 June 2014/Accepted: 22 August 2014/Published online: 7 November 2014

(C) Springer Science+Business Media New York and the Cardiovascular and Interventional Radiological Society of Europe (CIRSE) 2014

\begin{abstract}
Purpose Locoregional therapy for hepatocellular carcinoma (HCC) can be challenging in patients with a transjugular intrahepatic portosystemic shunt (TIPS). This study compares safety and imaging response of ablation, chemoembolization, radioembolization, and supportive care in patients with both TIPS and HCC.

Methods This retrospective study included 48 patients who had both a TIPS and a diagnosis of HCC. Twenty-nine of 48 (60\%) underwent treatment for HCC, and 19/48 (40\%) received best supportive care (i.e., symptomatic management only). While etiology of cirrhosis and indication for TIPS were similar between the two groups, treated patients had better baseline liver function (34 vs. $67 \%$ Child-Pugh class C). Tumor characteristics were similar between the two groups. A total of 39 ablations, 17 chemoembolizations, and 10 yttrium90 radioembolizations were performed on 29 patients.
\end{abstract}

Results Ablation procedures resulted in low rates of hepatotoxicity and clinical toxicity. Post-embolization/ ablation syndrome occurred more frequently in patients undergoing chemoembolization than ablation (47 vs. $15 \%$ ). Significant hepatic dysfunction occurred more frequently in the chemoembolization group than the ablation group. Follow-up imaging response showed objective response in $100 \%$ of ablation procedures, $67 \%$ of radioembolization procedures, and $50 \%$ of chemoembolization procedures $(p=0.001)$. When censored for OLT, patients undergoing treatment survived longer than patients receiving supportive care (2273 v. 439 days, $p=0.001$ ). Conclusions Ablation appears to be safe and efficacious for HCC in patients with TIPS. Catheter-based approaches are associated with potential increased toxicity in this patient population. Chemoembolization appears to be associated with increased toxicity compared to radioembolization.
S. A. Padia $(\bowtie) \cdot$ R. H. Chewning $\cdot$ M. J. Kogut .

C. R. Ingraham · G. E. Johnson · S. W. Kwan ·

W. L. Monsky $\cdot$ S. Vaidya $\cdot$ K. Valji

Section of Interventional Radiology, Department of Radiology,

University of Washington Medical Center, 1959 NE Pacific St.,

Box\# 357115, Seattle, WA 98195, USA

e-mail: spadia@uw.edu

R. H. Chewning

e-mail: rchewnin@uw.edu

M. J. Kogut

e-mail: kogutm@uw.edu

C. R. Ingraham

e-mail: cringa@uw.edu

G. E. Johnson

e-mail: gej@uw.edu

S. W. Kwan

e-mail: shakwan@uw.edu
W. L. Monsky

e-mail: wmonsky@uw.edu

S. Vaidya

e-mail: svaidya@uw.edu

K. Valji

e-mail:kvalji@uw.edu

\section{R. Bhattacharya}

Division of Gastroenterology and Hepatology, Department of Medicine, University of Washington Medical Center, Seattle,

WA, USA

e-mail: renuka@uw.edu

D. S. Hippe

Department of Radiology, University of Washington Medical

Center, Seattle, WA, USA

e-mail: dhippe@uw.edu 
Keywords Hepatocellular carcinoma - Ablation . Chemoembolization $\cdot$ yttrium-90 radioembolization . Liver transplant

\section{Introduction}

Well-defined treatment algorithms have been designed for management of patients with hepatocellular carcinoma (HCC) [1]. These treatments include transplantation, surgical resection, ablation, catheter-based embolization, medical therapy, and supportive care (i.e., symptomatic management only). Transjugular intrahepatic portosystemic shunt (TIPS) placement is the standard of care for patients with portal hypertension causing variceal bleeding or refractory ascites despite optimal medical management $[2,3]$. The natural history of patients who develop HCC in the setting of TIPS has not been extensively investigated. By diverting portal venous flow, TIPS renders the liver primarily dependent on hepatic arterial flow for its blood supply [4]. In theory, this should jeopardize liver function if arterial inflow is disrupted as well (such as in hepatic artery embolization). It is unclear if this alteration also affects the efficacy of intra-arterial therapies. Additionally, liver reserve may be more tenuous in the setting of large hepatic ablations $[5,6]$.

The purpose of this study is to retrospectively assess the safety and efficacy of locoregional therapies in patients with a TIPS and HCC. Specifically, clinical and biochemical toxicities, imaging response to treatment, and survival were the primary outcomes measured.

\section{Patients and Methods}

A retrospective study was conducted at a single institution by querying the hospital's patient information system to identify all patients, where HCC was diagnosed in the presence of indwelling TIPS, between January 12006 and December 312012.

All patients with a diagnosis of HCC were discussed at the institution's multidisciplinary liver tumor board. Diagnosis of HCC was made based on standard published criteria [1, 7]. Baseline demographic information was collected, including etiology and stage of cirrhosis, and performance status (Eastern Cooperative Oncology Group Score, ECOG). Child-Pugh and model for end-stage liver (MELD) scores were calculated at the time of HCC diagnosis. Baseline tumor characteristics were tabulated using the size and number of tumors and Barcelona clinic liver cancer (BCLC) tumor stage. The choice of treatment was made by a multidisciplinary liver tumor board. Ablation was considered the first option, if patients were eligible. If not eligible for ablation, either chemoembolization or radioembolization was performed. Being a retrospective study, there were some patients who may have been slightly outside the inclusion criteria, but underwent treatment based on consensus opinion and patient preference.

Patients were considered for ablation if all of the following criteria were met: (a) immediate transplantation or surgical resection was not an option, (b) maximum tumor diameter less than $3 \mathrm{~cm}$, (c) the absence of extrahepatic disease, and (d) tumor(s) technically amenable to ablation based on location within the liver. Tumors not technically amenable to radiofrequency ablation (RFA) were treated with either percutaneous ethanol injection (PEI) or irreversible electroporation (IRE). Technique for ablation was according to standard practice guidelines [8], using either a percutaneous or surgical approach. RFA was performed using either a single probe (Cool-tip, Covidien, Mansfield, MA) or a multi-pronged probe (StarBurst Talon, Angiodynamics, Latham, NY). In one case, a balloon occlusion catheter was inserted in the TIPS via a transjugular approach in order to temporarily occlude the TIPS prior to RFA (Fig. 1). For each PEI-treated tumor, two sessions were done using 20 gauge multi-sidehole needles (Bernadino, Cook, Bloomington, IN). IRE was performed in one case, using a four-needle configuration (Nanokinife, Angiodynamics, Latham, NY), due to the tumor's proximity to a large hepatic vein.

Patients were considered for transarterial chemoembolization if all of the following criteria were met: (a) potentially curative procedure (e.g., immediate transplantation, surgical resection, ablation) was not an option, (b) the absence of portal vein thrombosis, and (c) the absence of extrahepatic disease. If a tumor was not technically accessible for ablation, then embolization was performed. Embolization was then performed with doxorubicin drug-eluting LC Beads (Biocompatibles, Inc. Oxford, CT) or with an oil-based mixture (doxorubicin mixed with ethiodized oil) followed by infusion of $300-500$ um particles. Up to $50 \mathrm{mg}$ of doxorubicin was used in all cases of chemoembolization. Complete stasis of the feeding artery was avoided.

The yttrium- $90\left({ }^{90} \mathrm{Y}\right)$ radioembolization program using glass microspheres was initiated in our institution in 2010. Since then, radioembolization has been performed instead of chemoembolization in patients with TIPS, using the same inclusion criteria for chemoembolization. Radioembolization was performed according to standard operating procedure $[9,10]$. Dosimetry calculations were based on perfused liver volume, with an intended dose of 120 Gray to the perfused tissue. ${ }^{90} \mathrm{Y}$ glass microspheres 


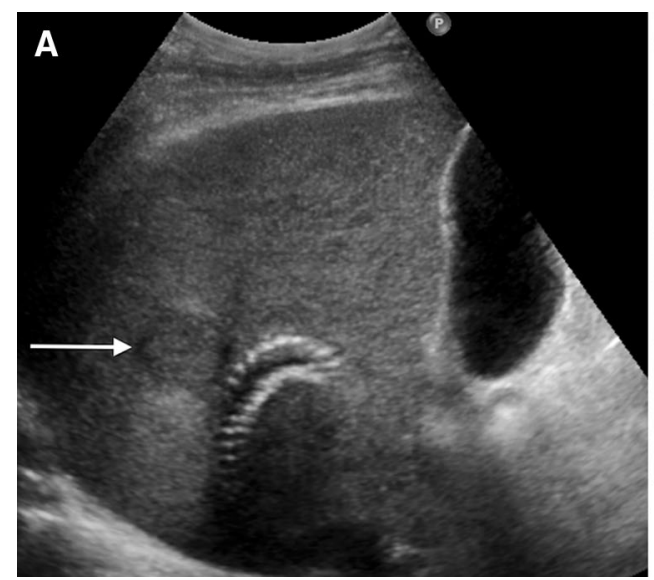

Fig. 1 Radiofrequency ablation for HCC in the setting of TIPS. a A $2 \mathrm{~cm}$ HCC (arrow) was identified in a 45-year-old male with cirrhosis and an indwelling TIPS. The tumor was adjacent to the TIPS, which could have caused a heat sink if thermal ablation was performed. b A balloon occlusion catheter was inserted through the TIPS via a right

(TheraSpheres, BTG, Ottawa, Canada) were used in all cases.

Follow-up visits and imaging (multiphase CT or MR) took place 1 month following the procedure, and every 3 months thereafter. Treatment was repeated if follow-up imaging demonstrated persistent enhancement of tumors. Toxicity was assessed at follow-up and retrospectively tabulated according to common terminology criteria for adverse events, version 4.0 [11]. Tumor response on imaging was assessed by measuring the index tumor and categorizing change in tumor size into four categories (complete response, partial response, stable disease, disease progression) as defined by the World Health Organization (WHO) and European association for the study of the liver (EASL) criteria [12-14].

\section{Statistical Methods}

Variables from patients who underwent treatment-ablation, chemoembolization, and ${ }^{90} \mathrm{Y}$ radioembolization-for HCC (treated group) and patients who received supportive care only were compared using the Mann-Whitney $U$ test (continuous variables) and Fisher's exact test (categorical variables). A permutation test based on the Chi-squared test statistic was used to detect significant differences among all treatments and then between pairs of treatments. The permutation test was implemented by permuting all rounds of the same treatment on the same patient as a group to preserve any correlation in toxicity response between successive rounds [15]. Imaging responses were compared between treatment types using the same permutation test approach as for the toxicity comparisons.

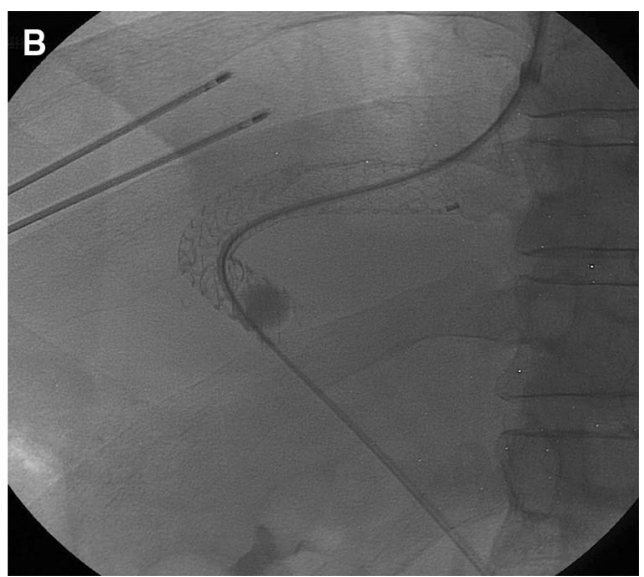

internal jugular approach. The balloon was inflated as radiofrequency ablation was performed after insertion of two probes. Final TIPS venogram after ablation (not shown) demonstrated continued patency of the TIPS

Survival time was analyzed using Cox proportional hazards regression models and cumulative incidence curves [16]. The time of HCC diagnosis was used as the reference time for all subsequent events, and the analysis was conducted both without censoring death by OLT as well as with censoring. Hazard ratios (HR) were used to summarize differences in survival between groups when the proportional hazards assumption was not rejected by a formal statistical test. Hazard ratios were tested using partial likelihood ratio tests and approximate Wald $95 \%$ confidence intervals (CIs) were calculated. The group variable separating treated and supportive care was made time-varying to account for the variable time to initial treatment. When different treatment types were compared, the groups were defined by the first type of treatment received.

All statistical calculations were conducted with the $\mathrm{R}$ statistical software package (version 2.14.1; R Foundation for Statistical Computing, Vienna, Austria). Throughout, two-tailed tests were used with $p<0.05$ denoting statistical significance.

\section{Results}

\section{Summary of Patients}

Patient demographics and clinical status at time of HCC diagnosis are presented in Table 1. Twenty-nine patients with TIPS underwent locoregional treatment for HCC, while 19 patients received supportive care (i.e., symptomatic management only). All patients had TIPS placed prior to the time of HCC diagnosis. 
Table 1 Patient demographics and clinical status at time of HCC diagnosis ( $n=48$ patients)

\begin{tabular}{|c|c|c|c|c|c|c|c|}
\hline \multirow[t]{2}{*}{ Variable } & \multicolumn{6}{|c|}{ No. $(\%)$ or median (range) } & \multirow[t]{2}{*}{$P$ value } \\
\hline & $\begin{array}{l}\text { Treated } \\
(n=29)\end{array}$ & $\begin{array}{l}\text { Supportive care } \\
(n=19)\end{array}$ & $P$ value & $\begin{array}{l}\text { Ablation } \\
(n=16)\end{array}$ & $\begin{array}{l}\text { TACE } \\
(n=9)\end{array}$ & ${ }^{90} \mathrm{Y}(n=4)$ & \\
\hline Sex & & & & & & & 0.71 \\
\hline Male & $22(76)$ & $16(84)$ & 0.72 & $11(69)$ & $8(89)$ & $3(75)$ & \\
\hline Female & $7(24)$ & $3(16)$ & & $5(31)$ & $1(11)$ & $1(25)$ & \\
\hline Age, years & $58(42-73)$ & $55(39-73)$ & 0.49 & $60(42-73)$ & $57(48-61)$ & $56(53-63)$ & 0.33 \\
\hline Cirrhosis etiology & & & & & & & 0.59 \\
\hline Alcohol & $3(10)$ & $2(11)$ & $>0.99$ & $2(12)$ & $0(0)$ & $1(25)$ & \\
\hline Hepatitis B & $1(3)$ & $1(5)$ & & $0(0)$ & $0(0)$ & $1(25)$ & \\
\hline Hepatitis C & $8(28)$ & $5(26)$ & & $5(31)$ & $2(22)$ & $1(25)$ & \\
\hline Hepatitis C + alcohol & $11(38)$ & $8(42)$ & & $5(31)$ & $5(56)$ & $1(25)$ & \\
\hline Hemochromatosis & $1(3)$ & $0(0)$ & & $1(6)$ & $0(0)$ & $0(0)$ & \\
\hline Cryptogenic & $5(17)$ & $3(16)$ & & $3(19)$ & $2(22)$ & $0(0)$ & \\
\hline Portal vein thrombosis & & & & & & & 0.29 \\
\hline No & $23(79)$ & $14(74)$ & 0.73 & $13(81)$ & $8(89)$ & $2(50)$ & \\
\hline Yes & $6(21)$ & $5(26)$ & & $3(19)$ & $1(11)$ & $2(50)$ & \\
\hline Total bilirubin, mg/dL & $1.9(0.9-5.7)$ & $2.8(1.1-18)$ & 0.020 & $1.6(0.9-5.7)$ & $2.0(0.9-5.6)$ & $1.6(1.2-2.4)$ & 0.40 \\
\hline Albumin, g/dL & $3.0(1.8-4.1)$ & $2.8(1.2-3.4)$ & 0.28 & $3.0(1.8-3.6)$ & $2.6(1.9-3.2)$ & $3.3(3.1-4.1)$ & 0.055 \\
\hline MELD score & $12(8-25)$ & $15(9-24)$ & 0.016 & $12(8-19)$ & $12(9-19)$ & $10(9-25)$ & 0.64 \\
\hline Child-pugh class & & & & & & & 0.87 \\
\hline B & $19(66)$ & $6(33)$ & 0.040 & $11(69)$ & $5(56)$ & $3(75)$ & \\
\hline $\mathrm{C}$ & $10(34)$ & $12(67)$ & & $5(31)$ & $4(44)$ & $1(25)$ & \\
\hline \multicolumn{8}{|l|}{ BCLC stage } \\
\hline A & $10(34)$ & $6(32)$ & 0.78 & $6(38)$ & $1(11)$ & $3(75)$ & 0.084 \\
\hline B & $4(14)$ & $2(11)$ & & $2(12)$ & $1(11)$ & $1(25)$ & \\
\hline $\mathrm{C}$ & $15(52)$ & $10(53)$ & & $8(50)$ & $7(78)$ & $0(0)$ & \\
\hline $\mathrm{D}$ & $0(0)$ & $1(5)$ & & $0(0)$ & $0(0)$ & $0(0)$ & \\
\hline \multicolumn{8}{|l|}{ ECOG status } \\
\hline 0 & $13(45)$ & $8(44)$ & 0.24 & $7(44)$ & $2(22)$ & $4(100)$ & 0.14 \\
\hline 1 & $13(45)$ & $5(28)$ & & $8(50)$ & $5(56)$ & $0(0)$ & \\
\hline 2 & $2(7)$ & $4(22)$ & & $1(6)$ & $1(11)$ & $0(0)$ & \\
\hline 3 & $1(3)$ & $0(0)$ & & $0(0)$ & $1(11)$ & $0(0)$ & \\
\hline 4 & $0(0)$ & $1(6)$ & & $0(0)$ & $0(0)$ & $0(0)$ & \\
\hline TIPS indication & & & & & & & 0.79 \\
\hline Variceal bleeding & $20(71)$ & $11(61)$ & 0.49 & $12(75)$ & $6(75)$ & $2(50)$ & \\
\hline Refractory hepatic hydrothorax & $3(11)$ & $1(6)$ & & $1(6)$ & $1(12)$ & $1(25)$ & \\
\hline Refractory ascites & $5(18)$ & $6(33)$ & & $3(19)$ & $1(12)$ & $1(25)$ & \\
\hline
\end{tabular}

$B C L C$ barcelona clinical liver cancer, $E C O G$ eastern cooperative oncology group, $H C C$ hepatocellular carcinoma, $M E L D$ model for end-stage liver disease, TACE transarterial chemoembolization, TIP transjugular intrahepatic portosystemic shunt; ${ }^{90} Y$ yttrium-90 radioembolization

HCC characteristics are summarized in Table 2. The most frequent indications for TIPS were variceal bleeding $(64 \%)$ and refractory ascites $(24 \%)$. There were no significant differences in lesion distribution, number of lesions, and the largest lesion dimension between the treated and supportive care groups but the AFP level exceeded $50 \mathrm{ng} / \mathrm{mL}$ more frequently in the supportive care group (41 vs. $11 \%, p=0.03$ ). There was a tendency for the chemoembolization and radioembolization groups to have 3 or more HCC lesions than the ablation group $(p=0.03)$, but there was no difference between the treated group as a whole and the supportive care group with regards to tumors $(p=0.7)$. There was one patient with portal vein thrombosis, who underwent chemoembolization, but the thrombus was non-occlusive in a segmental (non-lobar) location. 
Summary of Treatments

Of the 29 patients in the treated group, time from TIPS creation to first treatment ranged from 1 to 172 months (median: 33 months). Nine $(31 \%)$ patients had a single treatment, 9 (31\%) had two, 5 (17\%) had three, 4 (14\%) had four, and 1 (3\%) had five, for a total of 66 treatments. Of these 66 treatments, 39 (59\%) were ablation, 17 (26\%) were chemoembolization, and $10(15 \%)$ were ${ }^{90} \mathrm{Y}$ radioembolization. Of the 39 ablative treatments (surgical or percutaneous), 24 (62\%) were RFA, 14 (36\%) were PEI, and $1(2 \%)$ was IRE. Patients who underwent multiple rounds of treatment most often received the same class of treatment in each session.

\section{Toxicity Response to Treatment}

Clinical and biochemical toxicities after treatment are tabulated in Table 3. Those who underwent ablative treatment were significantly less likely to experience abdominal pain $(p=0.003)$, increased aspartate transaminase (grades $\geq 2$, $p<0.02$ ), and increased alanine transaminase (grades $\geq 2$, $p<0.004)$ than those who underwent chemoembolization (Fig. 2). There were marginally significant lower rates of increased aspartate transaminase (grade $\geq 2, p<0.051$ ) and increased alanine transaminase (grade $\geq 2, p<0.047$ ) after ${ }^{90} \mathrm{Y}$ treatments than after chemoembolization.

\section{Imaging Response to Treatment}

The best imaging responses for each treated lesion are summarized in Table 4. By EASL criteria, tumor response was significantly better after ablation than after chemoembolization $(p<0.001)$ or after radioembolization $(p=0.02)$. Tumor response was not significantly different between chemoembolization and radioembolization by WHO criteria $(p=0.14)$ or EASL criteria $(p=0.82)$.

\section{Survival After Treatment}

Median duration of follow-up was 704 days (range 37-3376 days). Of the 48 patients, 18 (38\%) died and 19 (40\%) underwent OLT. Figure 3 shows cumulative incidence curves for death, without and with censoring by OLT. When death was not censored by OLT, the curves from the two groups diverged initially but then eventually crossed. The median survival times were 2,265 days (treated) and 439 days (supportive care) $(p=0.13)$ and the hazard for death in the supportive care group was significantly higher than in the treated group $(\mathrm{HR}=8.3$; CI $2.4-29 ; p=0.001)$. When death was censored by OLT, the cumulative incidence curves diverged and this separation persisted over the study period.
As shown in Tables 1 and 2, the distributions of total bilirubin, MELD score, Child-Pugh class, and $\alpha$-fetoprotein (AFP) differed significantly between the treated and supportive care groups. While the number of deaths was low, an exploratory analysis was conducted to examine the effect of adjusting for each of these factors individually. The hazard ratios between supportive care and treated patients remained significant after each individual adjustment. When AFP $>50 \mathrm{ng} / \mathrm{mL}$ was included in the Cox model, the adjusted HR between supportive care and treated patients was 5.3 (CI $1.3-21 ; p=0.02$ ) and the adjusted $\mathrm{HR}$ for AFP $>50 \mathrm{ng} / \mathrm{mL}$ versus $\mathrm{AFP} \leq 50 \mathrm{ng} /$ $\mathrm{mL}$ was $\mathrm{HR}=4.8$ (CI 1.3-0.18; $p=0.02$ ).

\section{Survival of Different Treatment Groups}

An additional exploratory analysis of survival rates within each treatment group was conducted. Initially, treatment groups were defined by the first treatment performed. In the ablation $(n=16)$, chemoembolization $(n=9)$, and ${ }^{90} \mathrm{Y}$ $(n=4)$ groups, there were $5(31 \%)$ deaths, $2(22 \%)$ deaths, and $1(25 \%)$ death, respectively, and 8 (50\%), 4 $(44 \%)$, and $1(25 \%)$ OLTs in each group, respectively. There were no significant differences in survival between treatment groups ( $p>0.82$ for all comparisons).

After censoring death by OLT, the hazard ratios for supportive care group compared to each treatment were $\mathrm{HR}=13$ (CI 2.5-72; $p<0.001$ ) for ablation, $\mathrm{HR}=5.0$ (CI $0.9-27 ; p=0.035$ ) for chemoembolization, and $\mathrm{HR}=5.9$ (CI $0.7-49 ; p=0.045)$ for ${ }^{90} \mathrm{Y}$. There were no significant differences between treatment groups $(p>0.33$ for all comparisons). When the treatment group was made a time-varying variable which changed when a different type of treatment was performed rather than only using the first treatment type, the hazard ratios comparing the supportive care group to the ablation, chemoembolization, and ${ }^{90} \mathrm{Y}$ groups became $\mathrm{HR}=29 \quad(p<0.001), \mathrm{HR}=3.3$ $(p=0.096)$, and HR $=3.7(p=0.12)$, respectively. There was a trend toward better survival for those undergoing ablation than chemoembolization $(p=0.073)$ or ${ }^{90} \mathrm{Y}$ $(p=0.087)$ but no significant difference between chemoembolization and ${ }^{90} \mathrm{Y}(p=0.93)$.

\section{Discussion}

If the sequelae of portal hypertension fail to be controlled by medical management, TIPS may be necessary. By diverting portal flow away from the hepatic parenchyma, the TIPS renders the liver primarily reliant on hepatic arterial perfusion. This could potentially lead to hepatic ischemia or infarction if hepatic arterial flow was interrupted. In this sense, portal vein thrombosis (PVT) may be 
Table 2 HCC characteristics at time of HCC diagnosis ( $n=48$ patients)

\begin{tabular}{|c|c|c|c|c|c|c|c|}
\hline \multirow[t]{2}{*}{ Variable } & \multicolumn{6}{|c|}{ No. $(\%)$ or Median (range) } & \multirow[b]{2}{*}{$P$ value } \\
\hline & $\begin{array}{l}\text { Treated } \\
(n=29)\end{array}$ & $\begin{array}{l}\text { Supportive care } \\
(n=19)\end{array}$ & $p$-value & $\begin{array}{l}\text { Ablation } \\
(\mathrm{N}=16)\end{array}$ & $\begin{array}{l}\text { TACE } \\
(n=9)\end{array}$ & $\begin{array}{l}{ }^{90} \mathrm{Y} \\
(n=4)\end{array}$ & \\
\hline$>1$ year between TIPS and HCC diagnosis & $21(72)$ & $10(59)$ & 0.52 & $12(75)$ & $7(78)$ & $2(50)$ & 0.71 \\
\hline Lesion distribution & & & & & & & $>0.99$ \\
\hline Unilobar & $23(79)$ & $15(79)$ & $>0.99$ & $13(81)$ & $7(78)$ & $3(75)$ & \\
\hline Bilobar & $6(21)$ & $4(21)$ & & $3(19)$ & $2(22)$ & $1(25)$ & \\
\hline Number of lesions & & & & & & & 0.034 \\
\hline 1 & $20(69)$ & $11(58)$ & 0.75 & $10(62)$ & $7(78)$ & $3(75)$ & \\
\hline 2 & $6(21)$ & $5(26)$ & & $6(38)$ & $0(0)$ & $0(0)$ & \\
\hline$\geq 3$ & $3(10)$ & $3(16)$ & & $0(0)$ & $2(22)$ & $1(25)$ & \\
\hline Largest lesion dimension, $\mathrm{mm}$ & $23(11-55)$ & $26(9-70)$ & 0.25 & $24(13-55)$ & $23(11-33)$ & $29(20-36)$ & 0.55 \\
\hline $\mathrm{AFP}>50 \mathrm{ng} / \mathrm{mL}$ & $3(11)$ & $7(41)$ & 0.030 & $1(7)$ & $1(11)$ & $1(25)$ & 0.72 \\
\hline
\end{tabular}

$A F P \alpha$-fetoprotein, $H C C$ hepatocellular carcinoma, TACE transarterial chemoembolization, TIPS transjugular intrahepatic portosystemic shunt, ${ }^{90} Y$ yttrium-90 radioembolization

analogous to the presence of a TIPS, where the parenchyma relies exclusively on arterial perfusion. While there have been some series demonstrating safety of chemoembolization in the setting of PVT [17], PVT has been described as a relative contraindication to chemoembolization [1]. Therefore, theoretically, a TIPS may be a relative contraindication to chemoembolization.

Several series of chemoembolization in the setting of TIPS have been reported, with varying results [18-20]. In a small case series of six patients, Tesdal et al. demonstrated efficacy of chemoembolization and chemoembolization combined with PEI [19]. However, only complication rates during their procedure were recorded, and clinical followup with respect to toxicities was not conducted. In this series, two patients died of peritonitis or liver failure. In a larger retrospective series of 20 patients, Kang et al. demonstrated a low toxicity rate from chemoembolization [21]. In their cohort, only 1 of the 20 experienced a significant complication, bacterial peritonitis. Objective response rates were achieved in $70 \%$ of the patients. In a recent study of 158 patients comparing toxicity of chemoembolization in patients with and without TIPS, significantly higher rates of toxicity were identified in the TIPS group. Specifically, grade 3 bilirubin toxicity occurred in $60 \%$ of patients in the TIPS group, compared to only $18 \%$ in the non-TIPS group [20]. In their tumor response and survival analysis, objective response and overall survival were better in the non-TIPS group [22]. The authors concluded that unless the patients are candidates for liver transplantation, chemoembolization might not be safe. The results of our study are similar in terms of high rates of toxicity for chemoembolization.

Recently, Knuppel et al. reported their results of a casecontrol study, enrolling 60 patients with TIPS who were diagnosed with HCC, and comparing them to a cohort of 60 patients who had HCC without TIPS [23]. As expected, they showed a statistically significant shorter survival in the TIPS group compared to the non-TIPS group (17 vs. 24 months, respectively). While $47 \%$ of the patients were treated with transarterial chemotherapy, no severe hepatotoxicity was identified.

Compared to many forms of chemoembolization, arterial embolization with ${ }^{90} \mathrm{Y}$ glass microspheres is not a true embolization, as the embolic load is low and vessel patency is maintained after treatment. Therefore, hepatic ischemia would theoretically be avoided in patients who rely primarily on the hepatic artery for perfusion. Patients with unresectable HCC complicated by PVT do not seem to be at increased risk for hepatic failure, hepatic encephalopathy, worsening of pre-existing portal hypertension, or extension of pre-existing portal vein occlusion when administered ${ }^{90} \mathrm{Y}$ microspheres. Efficacy of ${ }^{90} \mathrm{Y}$ microspheres in patients with PVT was shown by Kulik et al. In this study, 37 patients with unresectable HCC had PVT (34\%), and demonstrated favorable toxicity after radioembolization [24]. Finally, in their large single cohort prospective observational series, Salem et al. have demonstrated safety of ${ }^{90} \mathrm{Y}$ glass microspheres in the setting of PVT, with median survival of 16 months in patients with Child A cirrhosis and branch PVT and without any increased toxicity compared to non-PVT patients [25].

In our study, while ${ }^{90} \mathrm{Y}$ radioembolization was associated with occasional hepatotoxicity, its frequency of clinical complications was lower than chemoembolization. A recent study evaluated twelve patients with TIPS who underwent ${ }^{90} \mathrm{Y}$ radioembolization for HCC [26]. Twentyfive percentage of patients experienced grade 3 or 4 bilirubin toxicity. Median survival censored for liver 
Table 3 Biochemical and clinical toxicity after each round of treatment session ( $n=66$ treatments)

\begin{tabular}{|c|c|c|c|c|}
\hline & \multicolumn{4}{|l|}{ No. $(\%)$} \\
\hline & $\begin{array}{l}\text { Ablation } \\
(n=39)\end{array}$ & $\begin{array}{l}\text { TACE } \\
(n=17)\end{array}$ & ${ }^{90} Y(n=10)$ & $\mathrm{p}^{\dagger}$ \\
\hline Leukopenia & $3(8)$ & $1(6)$ & $0(0)$ & 0.911 \\
\hline Thrombocytopenia & $0(0)$ & $0(0)$ & $0(0)$ & - \\
\hline $\begin{array}{l}\text { Increased aspartate } \\
\text { transaminase }\end{array}$ & $4(10)$ & $7(41)$ & $0(0)$ & 0.019 \\
\hline $\begin{array}{l}\text { Increased alanine } \\
\text { transaminase }\end{array}$ & $0(0)$ & $5(29)$ & $0(0)$ & 0.002 \\
\hline Increased total bilirubin & $\begin{array}{l}20 \\
(51)\end{array}$ & $12(71)$ & $6(60)$ & 0.607 \\
\hline $\begin{array}{l}\text { Increased alkaline } \\
\text { phosphatase }\end{array}$ & $0(0)$ & $2(12)$ & $0(0)$ & 0.054 \\
\hline Abdominal pain & $4(10)$ & $9(53)$ & $2(20)$ & 0.013 \\
\hline Abscess & $0(0)$ & $0(0)$ & $0(0)$ & - \\
\hline Biloma & $0(0)$ & $0(0)$ & $0(0)$ & - \\
\hline $\begin{array}{l}\text { Post-embolization/ } \\
\text { ablation syndrome }\end{array}$ & $6(15)$ & $8(47)$ & $2(20)$ & 0.17 \\
\hline Fatigue & $6(15)$ & $4(24)$ & $6(60)$ & 0.077 \\
\hline Ascites & $4(10)$ & $3(18)$ & $2(20)$ & 0.76 \\
\hline Encephalopathy & $4(10)$ & $4(24)$ & $0(0)$ & 0.21 \\
\hline Cholecystitis & $0(0)$ & $0(0)$ & $0(0)$ & - \\
\hline Pleural effusion & $3(8)$ & $1(6)$ & $0(0)$ & 0.80 \\
\hline Gastrointestinal bleed & $0(0)$ & $0(0)$ & $0(0)$ & - \\
\hline Pancreatitis & $0(0)$ & $0(0)$ & $0(0)$ & - \\
\hline Skin Erythema & $0(0)$ & $0(0)$ & $0(0)$ & - \\
\hline Alopecia & $0(0)$ & $0(0)$ & $0(0)$ & - \\
\hline
\end{tabular}

TACE transarterial chemoembolization; ${ }^{90} Y=$ yttrium-90 radioembolization

Biochemical toxicities were assessed if CTCAE (v.4) Grade 2 or higher

${ }^{\dagger}$ Overall test of any differences among treatments (permutation test)
Table 4 Imaging response of treated lesions $(\mathrm{N}=48$ lesions $*)$

\begin{tabular}{lllll}
\hline & No. (\%) & & \\
\cline { 2 - 5 } & $\begin{array}{l}\text { Ablation } \\
(n=28)\end{array}$ & $\begin{array}{l}\text { TACE } \\
(n=14)\end{array}$ & $\begin{array}{l}{ }^{90} \mathrm{Y}(n=6) \\
{ }^{\dagger}\end{array}$ & $p^{\dagger}$ \\
\hline WHO criteria & & & & \\
Tumor response & & & & 0.052 \\
Complete response (CR) & $0(0)$ & $2(14)$ & $0(0)$ & \\
Partial response (PR) & $1(4)$ & $2(14)$ & $2(33)$ & \\
Stable disease (SD) & $13(46)$ & $8(57)$ & $1(17)$ & \\
Progressive disease (PD) & $14(50)$ & $2(14)$ & $3(50)$ & \\
Objective response & $1(4)$ & $4(29)$ & $2(33)$ & 0.029 \\
(CR + PR) & & & & \\
EASL Criteria & & & & \\
Tumor response & & & & 0.009 \\
Complete response (CR) & $26(93)$ & $6(43)$ & $4(67)$ & \\
Partial response (PR) & $2(7)$ & $1(7)$ & $0(0)$ & \\
Stable disease (SD) & $0(0)$ & $5(36)$ & $1(17)$ & \\
Progressive disease (PD) & $0(0)$ & $2(14)$ & $1(17)$ & \\
Objective response & $28(100)$ & $7(50)$ & $4(67)$ & 0.001 \\
(CR + PR) & & & &
\end{tabular}

TACE transarterial chemoembolization, ${ }^{90} Y$ yttrium-90 radioembolization, WHO World Health Organization, EASL European association for the study of the liver

* 48 of 54 of treated lesions had imaging before and after

${ }^{\dagger}$ Overall test of any differences among treatments (permutation test)

transplantation was 498 days, and uncensored median survival was 827 days [16]. While the numbers are small, this preliminary study lends support to the safety of glass ${ }^{90} \mathrm{Y}$ radioembolization in the setting of TIPS.

Ablation has been largely presumed to be safe in patients with a TIPS or PVT. However, it is possible that a TIPS adjacent to a tumor could provide a heat sink during

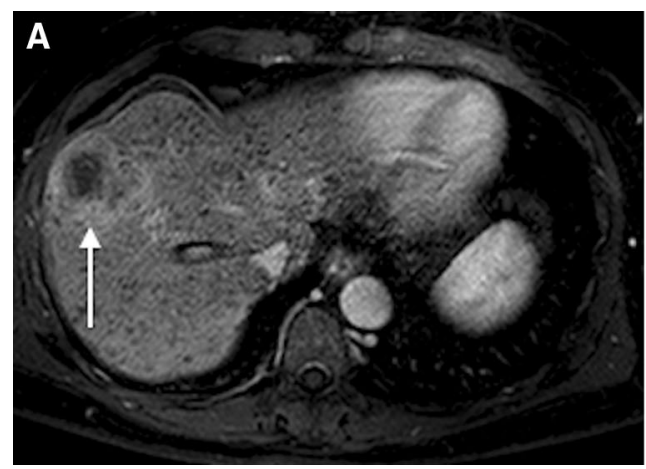

Fig. 2 Chemoembolization for HCC in the setting of TIPS. a In this 60-year-old male with cirrhosis and TIPS, single HCC in segment VIII of the liver was identified (arrow). He underwent selective transarterial chemoembolization of the anterior right hepatic lobe

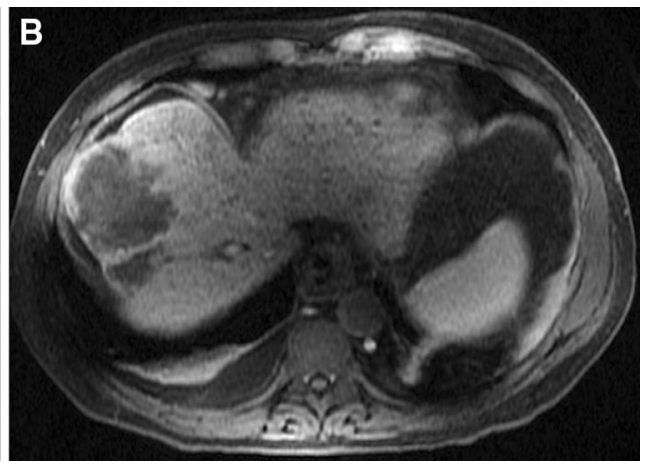

using doxorubicin drug-eluting beads. After the procedure, he was rehospitalized with acute liver failure. b Follow-up MR demonstrates infarction of the anterior right hepatic lobe 
Fig. 3 Cumulative incidence curves showing the probability of death for treated $(n=29)$ and supportive care $(n=19)$ groups. Crosses on curves indicate censored observation

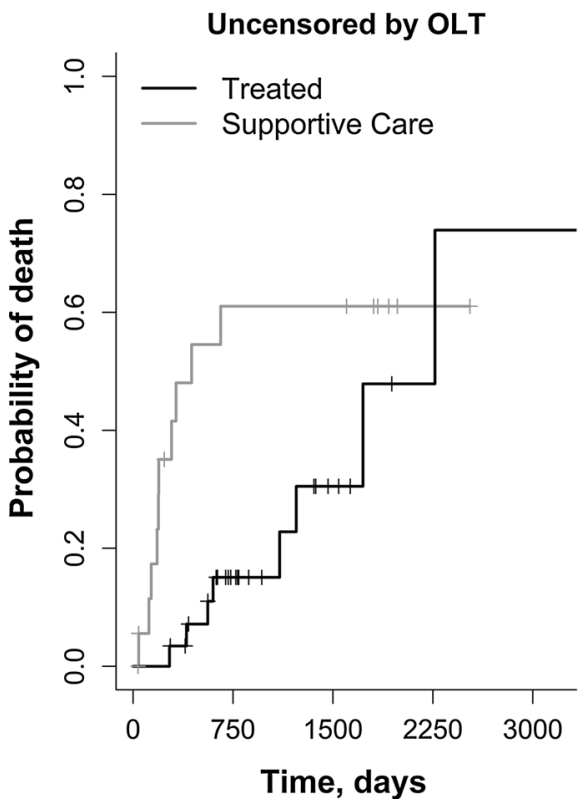

thermal ablation, thereby reducing its efficacy. In this series, this challenge was overcome in one patient using a technique to temporarily halt TIPS flow during ablation (Fig. 1). This technique has been described, although the effects of thermal ablation on the PTFE of the TIPS remain unknown [27].

Limitations to this study exist, including the inherent biases of retrospective investigations. The study has a relatively small sample size for each treatment arm with relative heterogeneity of response to treatment. The patients who received treatment were healthier overall as would be expected based on treatment recommendation by a multidisciplinary group. Survival in the setting of HCC is often limited by the patients' degree of underlying liver dysfunction rather than tumor burden. Patients with indwelling TIPS have already manifested the sequelae of portal hypertension, and median survival in these patients is clearly shorter than those without significant liver dysfunction $[28,29]$. Therefore, in the setting of TIPS, survival may be more limited by underlying liver disease rather than tumor.

In conclusion, this study describes the relative safety and efficacy of various treatment strategies for patients with HCC and TIPS. Based on these data, ablation is safe and effective and should be considered regardless of transplant status. Chemoembolization demonstrates increased toxicities compared to radioembolization, and perhaps should be considered with more trepidation depending on underlying liver function. Further studies are needed to address if these locoregional therapies lead to significantly prolonged survival in this patient population.
Conflict of Interest Siddharth Padia, MD, is a scientific advisor to BTG. Rush H. Chewning, Matthew J. Kogut, Christopher R. Ingraham, Guy E. Johnson, Renuka Bhattacharya, Sharon W. Kwan, Wayne L. Monsky, Sandeep Vaidya, Daniel S. Hippe, and Karim Valji declare that they have no conflict of interest.

Statement of Ethical Approval and Informed Consent This study was approved by the hospital's institutional review board. For this type of study, formal consent is not required.

Financial support There were no grants or financial support for this study.

\section{References}

1. Bruix J, Sherman M (2011) Management of hepatocellular carcinoma: an update. Hepatology 53(3):1020-1022

2. Runyon BA (2009) Management of adult patients with ascites due to cirrhosis: an update. Hepatology 49(6):2087-2107

3. Garcia-Tsao G, Sanyal AJ, Grace ND, Carey W (2007) Practice guidelines committee of the american association for the study of liver diseases, the practice parameters committee of the american college of gastroenterology. Prevention and management of gastroesophageal varices and variceal hemorrhage in cirrhosis. Hepatology 46(3):922-938

4. Patel NH, Sasadeusz KJ, Seshadri R, Chalasani N, Shah H, Johnson MS et al (2001) Increase in hepatic arterial blood flow after transjugular intrahepatic portosystemic shunt creation and its potential predictive value of postprocedural encephalopathy and mortality. J Vasc Interv Radiol 12(11):1279-1284

5. Chen TM, Huang PT, Lin LF, Tung JN (2008) Major complications of ultrasound-guided percutaneous radiofrequency ablations for liver malignancies: single center experience. J Gastroenterol Hepatol 23(8 Pt 2):e445-e450

6. Kong WT, Zhang WW, Qiu YD, Zhou T, Qiu JL, Zhang W et al (2009) Major complications after radiofrequency ablation for liver tumors: analysis of 255 patients. World J Gastroenterol 15(21):2651-2656 
7. Llovet JM, Ducreux M, Lencioni R, Di Bisceglie AM, Galle PR, Dufour JF et al (2012) EASL-EORTC clinical practice guidelines: management of hepatocellular carcinoma. J Hepatol 56(4):908-943

8. Ahmed M, Solbiati L, Brace CL, Breen DJ, Callstrom MR, Charboneau JW et al (2014) Image-guided tumor ablation: standardization of terminology and reporting criteria-A 10-year update. Radiology, Epub

9. Salem R, Thurston KG (2006) Radioembolization with 90Yttrium microspheres: a state-of-the-art brachytherapy treatment for primary and secondary liver malignancies. J Vasc Interv Radiol 17(8):1251-1278

10. Salem R, Thurston KG (2006) Radioembolization with 90Yttrium microspheres: a state-of-the-art brachytherapy treatment for primary and secondary liver malignancies. J Vasc Interv Radiol 17(9):1425-1439

11. National Cancer Institute. Common Terminology Criteria for Adverse Events (CTCAE) v.4.0 NIH Publication No. 09-7473. National Cancer Institute, National Institutes of Health, U.S. Department of Health and Human Services; 2009

12. Miller AB, Hoogstraten B, Staquet M, Winkler A (1981) Reporting results of cancer treatment. Cancer 47(1):207-214

13. Bruix J, Sherman M, Llovet JM, Beaugrand M, Lencioni R, Burroughs AK et al (2001) Clinical management of hepatocellular carcinoma. Conclusions of the Barcelona-2000 EASL conference. European Association for the Study of the Liver. J Hepatol 35(3):421-430

14. Riaz A, Miller FH, Kulik LM, Nikolaidis P, Yaghmai V, Lewandowski RJ et al (2010) Imaging response in the primary index lesion and clinical outcomes following transarterial locoregional therapy for hepatocellular carcinoma. JAMA 303(11):1062-1069

15. Davison AC (1997) Bootstrap Methods and Their Application. Cambridge University Press, Cambridge

16. Kalbfleisch JD, Prentice RL (2011) The statistical analysis of failure time data. Wiley, New York

17. Georgiades CS, Hong K, D’Angelo M, Geschwind J-FH (2005) Safety and efficacy of transarterial chemoembolization in patients with unresectable hepatocellular carcinoma and portal vein thrombosis. J Vasc Interv Radiol 16(12):1653-1659

18. Sakaguchi H, Uchida H, Maeda M, Matsuo N, Kichikawa K, Ohishi $\mathrm{H}$, et al. (1995) Combined transjugular intrahepatic portosystemic shunt and segmental Lipiodol hepatic artery embolization for the treatment of esophagogastric varices and hepatocellular carcinoma in patients with cirrhosis: preliminary report. Cardiovasc Intervent Radiol. Jan-Feb; 18(1):9-15. PMID: 7540504

19. Tesdal IK, Wikström M, Flechtenmacher C, Filser T, Dueber C (2006) Percutaneous treatment of hepatocellular carcinoma in patients with transjugular intrahepatic portosystemic shunts.
Cardiovasc Intervent Radiol. Sep-Oct; 29(5):778-84. PMID: 16779690

20. Kohi MP, Fidelman N, Naeger DM, LaBerge JM, Gordon RL, Kerlan RK (2013) Hepatotoxicity after transarterial chemoembolization and transjugular intrahepatic portosystemic shunt do two rights make a wrong? J Vasc Interv Radiol 24(1):68-73

21. Kang JW, Kim JH, Ko GY, Gwon DI, Yoon HK, Sung KB (2012) Transarterial chemoembolization for hepatocellular carcinoma after transjugular intrahepatic portosystemic shunt. Acta Radiol 53(5):545-550

22. Kuo YC, Kohi MP, Naeger DM, Tong RT, Kolli KP, Taylor AG et al (2013) Efficacy of TACE in TIPS patients: comparison of treatment response to chemoembolization for hepatocellular carcinoma in patients with and without a transjugular intrahepatic portosystemic shunt. Cardiovasc Intervent Radiol 36(5):1336-1343

23. Knuppel E, Bettinger D, Euringer W, Thimme R, Roessle M (2013) Influence of the transjugular intrahepatic portosystemic stent on firstline treatment of hepatocellular carcinoma. Hepatology 58(6):2211-2222

24. Kulik LM, Carr BI, Mulcahy MF, Lewandowski RJ, Atassi B, Ryu RK et al (2007) Safety and efficacy of 90Y radiotherapy for hepatocellular carcinoma with and without portal vein thrombosis. Hepatology 47(1):71-81

25. Salem R, Lewandowski RJ, Mulcahy MF, Riaz A, Ryu RK, Ibrahim S et al (2010) Radioembolization for Hepatocellular Carcinoma Using Yttrium-90 Microspheres: A Comprehensive Report of Long-term Outcomes. Gastroenterology 138(1):52-64

26. Donahue LA, Kulik L, Baker T, Ganger DR, Gupta R, Memon K et al (2013) Yttrium-90 radioembolization for the treatment of unresectable hepatocellular carcinoma in patients with transjugular intrahepatic portosystemic shunts. J Vasc Interv Radiol 24(1):74-80

27. Pua U, Punamiya S (2012) transjugular intrahepatic portosystemic shunt occlusion via modified pringle maneuver for radiofrequency ablation of nearby tumor. J Vasc Interv Radiol 23(4):563-565

28. García-Pagán JC, Caca K, Bureau C, Laleman W, Appenrodt B, Luca A et al (2010) Early use of TIPS in patients with cirrhosis and variceal bleeding. N Engl J Med 362(25):2370-2379

29. Salerno F, Merli M, Riggio O, Cazzaniga M, Valeriano V, Pozzi $M$ et al (2004) Randomized controlled study of TIPS versus paracentesis plus albumin in cirrhosis with severe ascites. Hepatology 40(3):629-635 